\title{
The Impact of Consecutive Interpreting Training on the L2 Listening Competence Enhancement
}

\author{
Tongtong Zhang ${ }^{1} \&$ Zhiwei $\mathrm{Wu}^{2}$ \\ ${ }^{1}$ International College, Guangdong University of Foreign Studies, Guangzhou, China \\ ${ }^{2}$ Faculty of English Langauge and Culture, Guangdong University of Foreign Studies, Guangzhou, China \\ Correspondence: Tongtong Zhang, International College, Guangdong University of Foreign Studies, Higher \\ Education Mega Center, Panyu District, Guangzhou City, Guangdong Province, 510006, China. Tel: \\ 86-13928990038. E-mail: 200820426@oamail.gdufs.edu.cn
}

Received: November 22, 2016 Accepted: December 20, 2016 Online Published: December 21, 2016

doi: 10.5539/elt.v10n1p72 URL: http://dx.doi.org/10.5539/elt.v10n1p72

\begin{abstract}
In recent years, a growing number of people have taken up interpreting training, with the intention of not only developing interpreting skills, but improving language proficiency as well. The present study sets out to investigate the impact of English-Chinese consecutive interpreting (CI) training on the enhancement of the second language (L2, English) listening competence. An empirical study was conducted on 50 interpreting student beginners to assess the effect of two different interpreting training modes on students' English listening ability. The study indicates that CI training can enhance students' L2 listening competence, specifically intensive listening skill and selective listening skill, but to a varying extent. Active listening, when trained as a stand-alone rather than a built-in component in the curriculum, contributes more to improving students' listening ability. In view of this, pedagogical implications for interpreting training and L2 listening teaching are discussed.
\end{abstract}

Keywords: consecutive interpreting training, L2 listening competence, active listening

\section{Introduction}

Interpreting education, which was initially institutionalized in Europe after the Second World War (Bowen, 1995 ,), grew in size and economic significance remarkably in the latter half of the twentieth century. It is increasingly acknowledged that formal training in interpreting and translation schools is the most feasible way to teach abilities and train professionals catering to the market demand (Gile, 2009). Consequently, the last few decades have witnessed a dramatic growth in the number of interpreter and translator training programs and institutions in many parts of the world. In China, interpreting and translation officially became a bachelor degree program in 2006 and MTI (Master in Translation and Interpreting) was established in the following year. By 2016, 152 universities have set up bachelor degree programs in interpreting and translation and 206 universities have offered MTI programs (Translators Association of China, 2016).

As $\mathrm{Wu}$ (2016) observes, there has been a substantial difference in the language proficiency requirement between the institutes in mainland China and those overseas. For instance, in Middlebury Institute of International Studies at Monterey (MIIS), candidates applying for Translation and Interpretation Postgraduate Program are required to provide TOEFL (100 overall) or IELTS ( 7.5 overall) scores as well as take an "early diagnostic test (EDT)" to prove their second language proficiency (MIIS, 2016). Likewise, in Fu Jen Catholic University in Taiwan, language proficiency of both A and B language is highly requested: "An excellent command of the intricate and sophisticated aspect as well as a flexible use of different registers of A language; near-native level in listening and reading and full mastery of speaking and writing of B language" (Fu Jen Catholic University, 2016). As can be seen, the postgraduate programs in these two institutions set a high language proficiency level for prospective interpreting students. By contrast, MTI programs in mainland China do not list language proficiency as a requirement, since "interpreting learners do not necessarily have to be English majors" and "students of non-English majors are highly welcomed to apply for MTI programs", which are explicitly stated in the MTI Training Schemes (Ping, 2011). This echoes a few previous studies from mainland China (Zhan, 2013), Hong Kong (Yan, Pan, \& Wang, 2010) and Korea (Sung, 2010), which suggest that "to improve English proficiency" is rated among the top three learning motives by interpreting students. 
Normally, interpreter training programs are not designed to address the demand of improving learners' language proficiency, since it is presumed that "students already have the ability to carry messages across linguistic barriers" (Ilg \& Lambert, 1996). However, the linguistic prerequisites are not always met by the candidates in the entrance exams into such programs and interpreting trainers may find that students lack both "adequate active and passive language command" when they start interpreting classes (Carroll, 1978). In China, interpreting students' L2 listening competence in particular has proven to be a bottleneck in the initial stage of interpreting learning, which hinders both interpreting quality and interpreting education effect (Zhong \& Wang, 2009).

So far, several scholars such as Gile (2009), Sawyer (2004) and Angelelli (2006) have touched upon the role of listening in interpreting training. Angelelli (2007, 2008), Jesus and Mayor (2015) and Cai et al. (2015) have revealed the importance of L2 proficiency especially listening proficiency in interpreting performance. By contrast, there is a scarcity of studies on the impact of interpreting training on L2 listening competence. Despite the increasing interest in this topic recently, few studies have empirically proven that interpreting training can indeed improve learners' L2 listening competence. The present paper, therefore, reports on an empirical study to examine the impact of English-Chinese consecutive interpreting training on the enhancement of L2 listening competence. Hopefully, the findings will shed light on the pedagogy and researches in the field of interpreting as well as L2 listening.

\section{Literature Review}

In order to examine the topic in question, relevant studies are briefly reviewed in this part. To begin with, there is the necessity to understand how L2 listening competence is defined, what types of skill it involves and how it can be improved. We then continue to analyze the role of listening in interpreting, including how important it is and how active listening is trained in interpreting class. Based on these two parts, the relationship between CI training/performance and L2 proficiency especially L2 listening is discussed as well as the rationale of the present study is revealed. It is also necessary to have a look at and compare the curriculums of different interpreting programs in several key institutions across the world, which lays a foundation for the research followed.

\subsection{The Nature and Enhancement of L2 Listening Competence}

The past few years have found a growing interest in the mental processing of L2 listeners, the components of listening skills as well as the ways in which L2 listening competence can be enhanced. It is generally believed that listening proficiency entails the competence to process acoustic/visual input so as to construct a mental model or representation as the foundation for some form of spoken or written response. Such internal cognitive processing, together with individual characteristics as well as external contextual factors make up a "social-cognitive framework" for describing L2 listening ability (Taylor \& Geranpayeh, 2011). According to Anderson and Lynch, listening is comprised of hearing ("speech perception") and understanding ("interpretation") and it is an active process of constructing meaning based on one's linguistic and extra-linguistic knowledge (1988).

There are various ways to define and categorize listening proficiency, among which are taxonomies of general listening skills, sub-skills and strategies (Buck, 2001; Hughes, 2003). Field (2008) points out the significance of taxonomies in teaching listening skills and claims that certain test question or test type might be more focused on one particular sub-skill. According to Rost, listening skills can be divided into six types: intensive, selective, interactive, extensive, responsive and autonomous, each of which entails a different listening ability and thus involves different activities or tasks (2011). For instance, "intensive listening skill" refers to the ability to listen very closely for "precise sounds, words, phrases, grammatical units and pragmatic units" (Rost, 2011). As a result, dictation test, which is mainly designed to examine the ability of listening for details, fits into this category. Quite differently, "selective listening skill" is linked to identifying main ideas, "extracting key information" and "gathering specific information to perform a task" and summary writing after listening tends to emphasize such skill (Rost, 2011). As a matter of fact, dictation and summary writing after listening prevail in a wide range of tests. While dictation test has long been used in TEM-4 (Test of English Majors, Band 4) in China, summary writing after listening is prevalent in numerous tests like CATTI 3 (China Accreditation Test for Translators and Interpreters, Level 3) and TOEFL.

Among the four main language skills, listening has been viewed as the most difficult skill for learners to acquire and teachers to teach (Vandergrift, 2004; Field, 2008), possibly due to the fact that listening skill is developed without apparent effort or attention by most people. Several scholars carry out researches into the ways of teaching L2 listening. Field (2008) has done extensive and in-depth studies on L2 listening and elaborates on the strategies and methodology that can be employed to teach and improve students' listening ability. Yang (2003) 
conducts an experiment on Chinese EFL leaners to examine the effect of systematic dictation practice on their language proficiency, which shows that this practice significantly improves students' listening ability. Actually, dictation test is not only commonly used in English tests for assessing learners' L2 proficiency but also a popular research topic in China.

The examination of relevant literature enables us to operationalize two sub-skills: intensive listening skill and selective listening skill, which are frequently evaluated in national standardized tests, English proficiency tests and classroom teaching.

\subsection{The Role of Listening in Consecutive Interpreting (CI)}

Gile splits CI into two phases: the comprehension phase and the speech production phrase. Phase one involves listening and note-taking where interpreting $=\mathrm{L}+\mathrm{N}+\mathrm{M}+\mathrm{C}$ (L: listening and analysis, N: note-taking, M: short-term memory operations and $\mathrm{C}$ : coordination) while phase two is primarily a target-speech production process where interpreting $=\mathrm{Rem}+\mathrm{Read}+\mathrm{P}+\mathrm{C}$ (Rem: remembering, Read: note-reading, P: production and $\mathrm{C}$ : coordination) (2009). Listening and analysis component, speech production component and short-term memory component constitute the total CI effort (Gile, 2009). Each component occupies a portion of processing capacity and if interpreters' total processing capacity falls short of demand, problems arise. Excellent listening and analysis ability contributes a lot to saving processing capacity, since note-taking takes up a large proportion of it in CI (Gile, 2009). As can be seen, listening and analysis ability is the very first step leading to the success of CI.

It is worth noting that "listening and analysis" in interpreting is a bit different from L2 listening comprehension, since the focus of the former is on the analysis process whereas the latter on understanding meaning and language acquisition ( $\mathrm{Lu}, 2009)$. Lu clarifies the differences between the two and contends that "listening and analysis" requires interpreters to listen actively and constantly process the upcoming information "so that it can be easily stored and retrieved for the purpose of interpreting" (2009). In this sense, "listening and analysis" shares many similarities to the term "active listening". For the sake of consistency, the authors use "active listening" in the present study while "listening and analysis" will only be used when Gile (2009) and Lu (2009) are cited.

According to Hunsaker and Alessandra (2008), people who are listening fall into one of the four categories: non-listener, marginal listener, evaluative listener and active listener. Among them, active listening is the most effective level, which requires the largest amount of concentration and sensitivity and listeners should listen with full attention for the content, intent and feeling of the speaker. The role of active listening in CI has been highlighted by many scholars. Sawyer lists it as an essential element in the skill-based training curriculum of the Graduate School of Translation and Interpretation (GSTI) at MIIS and stresses the importance of "sharpening listening ability" in CI (2004). Angelelli points out the necessity of enhancing active listening skill which is conducive to the cognitive processing in $\mathrm{CI}$ and includes it in the foundational skills for students' practice in health-care interpreting education (2006).

\subsection{Correlation between Interpreting Performance/Training and L2 Proficiency}

Some scholars have investigated the correlation between interpreting performance/training and L2 proficiency. Angelelli $(2007,2008)$ conducts a study on the interconnection between language proficiency and interpreting skills in medical interpreting education. Jesus and Mayor (2015) carry out an experiment on Spanish undergraduate interpreting students to test the role of L2 proficiency in interpreting performance and finds that L2 listening training largely enhances CI performance. They also recommend that L2 listening training should be included in the interpreting program curriculum. Cai et al. (2015) collect data from student interpreters in China and indicate that L2 proficiency especially listening and speaking proficiency significantly correlates with CI performance at the beginning stage of interpreting training. They further argue that "learners may benefit more when instructors design exercises to improve their L2 proficiency compared with exercises to improve their memory capacity or lexical retrieval efficiency" (2015).

However, the impact of interpreting training on L2 listening competence is much less researched. Sung (2014) probes into the effectiveness of using TED in Korean undergraduate interpreting classroom to enhance students' listening competence. Answers to two interview questions suggest that using TED can spur students' active listening and hence their listening skills. Yet since the pre-test-post-test method was not adopted in the study, the results seem to lack adequate empirical support. In mainland China, Wang (2009), Han and Chen (2011) realize the contribution of interpreting training to teaching L2 listening and speaking to non-English majors and believe that it can arouse students' interest, improve listening efficiency as well as oral expression. Nevertheless, their studies only explore the possibility of employing interpreting training methods in L2 listening and speaking class while concrete evidence from experiment is not provided. In a word, hardly any empirical studies on the impact 
of CI training on L2 listening competence are found in China so far.

\subsection{Curriculum of Interpreting Programs in Different Institutions}

Leading institutions of interpreting and translation studies in the West, especially members of CIUTI (the International Permanent Conference of University Institutes of Translators and Interpreters) seem to reach a consensus that when students are admitted, they have already had a "near-perfect" command of their working languages and language skills training at interpreter school "should be limited to the acquisition and improvement of conference-specific and LSP-specific phraseology and terminology" (Gile, 2009). Consequently, there has been a trend in the West to differentiate interpreting training from language training (Gile, 2009). For example, the compulsory/core modules of MA Conference Interpreting Program in the University of Leeds (The University of Leeds, 2016) and the University of Manchester (The University of Manchester, 2016) (both are members of AIIC, International Association of Conference Interpreters) are basically skill-oriented, with interpreting skills training such as short-term memory, note-taking and public speaking placed first. Also included in the curriculum are consecutive and simultaneous interpreting, methods and approaches in translation studies as well as specialized translation (topic-based). Judging from the curriculum of the two programs, listening training seems to be a built-in part of the syllabus. On the contrary, language enhancement is a part of the skill-based progression curriculum in the first year of GSTI at MIIS, which offers a wide range of electives ranging from vocabulary, critical thinking to text analysis for improving students' language ability. Additionally, active listening skill, among many other skills is highlighted in the CI training portfolio (Sawyer, 2004).

In China, "English Interpreting" in Guangdong University of Foreign Studies (GDUFS) (GDUFS, 2007) and "Chinese-English Interpreting" in Sichuan University (Sichuan University, 2008) are enlisted in the "National Excellent Course Scheme" certified by Ministry of Education. Both courses share some similarities in teaching contents, which mainly consist of skill-based modules, highlighting interpreting skills training as well as knowledge-based modules, focusing on knowledge-building concerning key aspects of different topics such as politics and foreign affairs, education and culture, environment, etc. Similarly, active listening is not trained independently from other interpreting skills training.

Obviously, except for MIIS, language training is not much factored in the curriculum and teaching objectives in these programs. Chances are that interpreting trainers might incorporate it in their classes, but it is apparently not an independent component in most institutions. However, as is mentioned earlier, a growing number of scholars have realized the inadequacy of students' L2 listening competence as well as the critical role of active listening in interpreting. Thus, they have begun to integrate more listening training in interpreting education. Lu (2009) from Beijing Foreign Studies University suggests that listening and analysis ability can be trained as a separate module or at least a stand-alone component independently from other interpreting skills training. Moreover, he identifies eleven skills needed for listening and analysis in interpreting process and puts forward relevant teaching techniques for developing each skill, ranging from separating words from meaning, chunking sense group to paraphrasing and coordinating senses. He also applies such techniques in teaching interpreting in the Graduate School of Translation and Interpretation. Xu (2010) by borrowing from the theoretical framework of discourse analysis, elaborates on the nine-step procedure of training listening in interpreting, such as identifying main information, analyzing logical clues, grasping key words and so on. He specially offers an interpreting listening course with 36 teaching hours for sophomore students in China Foreign Affairs University, which in his opinion lays a foundation for English-Chinese CI training in the third year of study.

As can be seen, many studies have indicated that L2 proficiency especially listening competence plays a vital role in CI performance and training, yet the impact of CI training on the enhancement of L2 listening competence is not empirically explored, which necessitates the need to examine this question. Furthermore, while language enhancement is only provided by MIIS, active listening seems to be trained in different ways in different institutions. Which curriculum is more optimally designed? Is it better to train active listening as a built-in part integrated with interpreting skills training as in most institutions or as a stand-alone component as in Lu's (2009) and Xu's (2010) classes? Can interpreting training enhance students' L2 listening competence? If yes, what types of skill can be improved? These are some of the questions that triggered the authors to initiate the current study.

\section{Research Design}

\subsection{Research Questions}

This empirical study attempts to address the relationship between CI training and L2 (English) listening competence. Specifically, we operationalize "listening competence" into two variables: (a) intensive listening skill (listening for details) and (b) selective listening skill (listening for gist). Therefore, we raise three research 
questions:

1) Does CI training contribute to the improvement of intensive listening skill?

2) Does CI training contribute to the improvement of selective listening skill?

3) Do different training modes have different impact on the intensive and selective listening skills?

\subsection{Participants and Experiment Conditions}

Participants involved in this study were drawn from two parallel undergraduate classes and randomly assigned into a Control Group (CG, $n=24)$ and an Experimental Group ( $E G, n=26)$. All the participants majored in Translation and Interpreting in GDUFS. At the time of the pre-test, none of them had received any interpreting training.

As is demonstrated in the previous section, two interpreting training modes simultaneously exist in different institutions. The first one adopted by most institutions is more conventional, with a built-in listening training throughout the different stages of training in the syllabus whilst the second one adopted by a handful of institutions puts listening training as a stand-alone component in the syllabus. Consequently, we arranged these two experiment conditions to test whether or to what extent different interpreting training modes would enhance students' L2 listening competence (intensive listening skill and selective listening skill in particular). CG students received the first and the more prevalent training mode (hence the name, "control group") whereas EG students received the second training mode with comparatively independent listening training. As a matter of fact, the two syllabi share the same content, with the only difference being the arrangement of the active listening training. In CG, active listening training was scattered and built into interpreting skills training whereas in EG, active listening training was scheduled as a stand-alone component at the beginning of the course. More details about the two syllabi are given in Table 1. CG and EG were taught by two different teachers, who had followed the corresponding syllabus for over five years. We used two different teachers, because these two syllabi were different from each other and the two classes shared adjacent time schedule. If one teacher had been asked to teach in two different syllabi in such a short period of time, we believed that the validity of the teaching would be very low. In addition, these two teachers were both well-versed in these two training methods, which led to great ecological validity of this experiment. As a way to control the basic parameters of this experiment, two teachers had a detailed time arrangement for each training activity in each weekly class, to ensure that students received the same amount of training in terms of listening. The only difference was the way they received active listening training: built-in vs. stand-alone.

Table 1. Syllabi of the two CI Training Modes

\begin{tabular}{|c|c|c|c|}
\hline CG (built- & & EG (stanc & de) \\
\hline Timeline & Contents & Timeline & Contents \\
\hline Week 1 & Shadowing + chunking information & Week 1 & $\begin{array}{l}\text { Active listening: } \\
\text { identifying key words }\end{array}$ \\
\hline Week 2 & Shadowing + idea progression & Week 2 & $\begin{array}{l}\text { Active listening: chunking } \\
\text { information }\end{array}$ \\
\hline Week 3 & Shadowing + causal relation & Week 3 & $\begin{array}{l}\text { Active listening: idea } \\
\text { progression }\end{array}$ \\
\hline Week 4 & $\begin{array}{l}\text { Shadowing }+ \text { temporal and ordinal } \\
\text { relation }\end{array}$ & Week 4 & $\begin{array}{l}\text { Active listening: } \\
\text { casual relation }\end{array}$ \\
\hline Week 5 & $\begin{array}{l}\text { Short-term memory training }+ \\
\text { identifying key words }\end{array}$ & Week 5 & $\begin{array}{l}\text { Active listening: } \\
\text { temporal and ordinal relation }\end{array}$ \\
\hline Week 6 & $\begin{array}{l}\text { Short-term memory training }+ \\
\text { chunking information }\end{array}$ & Week 6 & $\begin{array}{l}\text { Active listening: } \\
\text { visualizing structure }\end{array}$ \\
\hline Week 7 & $\begin{array}{l}\text { Short-term memory training }+ \text { causal } \\
\text { relation }\end{array}$ & Week 7 & Shadowing \\
\hline Week 8 & Short-term memory training + & Week 8 & + Short-term \\
\hline
\end{tabular}


temporal and ordinal relation

Week 9

Week $10-14$

Week $15-16$
Short-term memory training + visualizing structure

Note-taking

Delivery memory

Short-term memory

Week 9

Week $10-14$

Note-taking

Week $15-16$

Delivery

\subsection{Testing Instruments}

Two tests were designed and conducted to assess participants' L2 listening competence. The first one was a dictation test. Participants were required to dictate a short passage, numbering 162 words, about the phenomenon of flash-mob. Following the design of TEM-4, the passage was played three times. For the first time, the passage was read at a normal speed; for the second time, the passage was paused by 15 segments to allow participants to write down what they heard; for the third time, the passage was read at a normal speed once again so that participants can check their answer. As dictation test was a mandatory component in the TEM-4, which all participants had taken five months before the study, they were all familiar with the testing format.

The second test was designed to test participants' ability to summarize the information points in a mini-lecture. The mini-lecture, lasting 2 minutes and 52 seconds at a normal speed, was about some safety rules for those interested in kite-surfing. Following the design of CATTI, participants were required to write a summary of the mini-lecture right after they listened to it. The summary must be under 100 words, and the recording was played once only.

These two tests were piloted in a different group of students $(n=25)$, who were from a third class in the same program. Independent sample t-test showed that both tests were able to separate the highest 8 performers (i.e. top $33.33 \%$ ) from the lowest 8 performers (for dictation, $\mathrm{t}=4.76, \mathrm{p} .<0.001$; for summary, $\mathrm{t}=7.49, \mathrm{p} .<0.001$ ), suggesting that both of the tests were valid.

\subsection{Procedure and Data Collection}

As this study attempts to address the question of whether CI training would improve students' L2 listening ability, a pre-test-post-test design was adopted. Specifically, as the pre-test, the two listening tests explained in the previous subsection were administered to the 50 participants before they began their CI training. 16 weeks later, as the post-test, the same listening tests were once again administered to the participants. Some might argue that using the same tests would lead to score inflation, because students might remember the test contents. While we acknowledge this possibility, we must point out that it is even more risky to use different test contents, because "even subtle differences in a task can affect performance profoundly" (Thelen \& Corbetta, 2002). In light of this, we stuck to the same test materials, a common practice endorsed by many other researchers (Larsen-Freeman 2006; Cai et al., 2015), who were interested in tracking the changes of L2 and/or interpreting performance over a period of time.

As regards data collection, the scores of dictation and summary in the pre-tests and post-tests were obtained in the following way. Two research assistants were asked to score students' performance independently. In the dictation test, students were awarded 1 point if they got one word correct. The total score, therefore, was the sum of the total correct words (out of 162). In case of spelling mistakes or incorrect tenses, half a point was awarded if the misspelt word did not hinder understanding (See Table 2). In the summary test, 20 pieces of information were identified by the authors as necessary in the reproduction of the mini-lecture. Among them, 10 were regarded minor information, each of which was worthy of 1 point, and another 10 were major information, each worthy of 2 points. The total score for summary, therefore, was 30 . If students got the message right, they were awarded the full point(s). In the case where students touched upon but did not sufficiently convey the intended message, they were awarded half of the point(s) (See Table 3). Correlation analysis showed that the two research assistants had a high inter-rater reliability in scoring the two tasks (for dictation, r. $=0.952, \mathrm{p} .<0.001$; for summary, $\mathrm{r}=0.967, \mathrm{p} .<0.001)$. The average of the two assistants' scores was taken as the final score for the participants. 
Table 2. Dictation scoring scheme

\begin{tabular}{llll}
\hline Expected answer & Students' answer & Score & Remark \\
\hline apparent & apparent & 1 & Correct rendition \\
& aparent & 0.5 & Spelling mistake \\
apparel & 0 & Wrong word; hinder comprehension \\
involved & involved & 1 & Correct rendition \\
& involve / involves & 0.5 & incorrect tense \\
& evolved & 0 & Wrong word; hinder comprehension \\
\hline
\end{tabular}

Table 3. Summary scoring scheme

\begin{tabular}{llll}
\hline Expected answer & Category & Students' answer & Score \\
\hline serious and even fatal & Major information & serious and fatal accidents & 2 \\
accidents & & Some accidents & 1 \\
& (missing) & 0 \\
a growing number of & Minor information & more and more people & 1 \\
people & & people & 0.5 \\
& & (missing) & 0 \\
\hline
\end{tabular}

In addition to the quantitative data described above, we also collected qualitative data to solicit students' perception about the relationship between CI training and the enhancement of listening competence. At the end of the post-test, students were given a short questionnaire, containing three open-ended questions. The first one asked about students' perception (satisfaction, usefulness, adequacy, etc.) about the listening training in the interpreting course; the second one tapped into their perception about the benefits (listening ability improvement in particular) brought by CI training; the final one prompted them to identify any unresolved issues or suggestions for future improvement. The questionnaire was voluntary, and as it turned out, 43 students turned in their questionnaires, 39 of which had complete answers.

\section{Results and Discussion}

\subsection{Descriptive Data}

The descriptive data of the pre-test and the post-test are presented in Table 4. Means are provided outside the parenthesis, while standard deviations (SD) are provided in the parenthesis.

Table 4. Descriptive data of the Pre-test and the Post-test

\begin{tabular}{lllll}
\hline Group & Pre-test & & Post-test & \\
\cline { 2 - 5 } & Dictation & Summary & Dictation & Summary \\
\hline CG & $140.86(7.31)$ & $15.35(2.43)$ & $150.38(5.87)$ & $17.29(2.69)$ \\
EG & $144.04(6.59)$ & $15.29(3.10)$ & $152.65(5.76)$ & $23.83(2.75)$ \\
\hline
\end{tabular}

\subsection{Intensive Listening Skill}

A paired-sample t-test showed that both groups scored significantly higher in the post-test than in the pre-test in the dictation test (for CG, $\mathrm{t}=10.23, \mathrm{p} .<0.001$; for $\mathrm{EG}, \mathrm{t}=8.07, \mathrm{p} .<0.001$ ). That means after 16 weeks of CI training, both groups improved their intensive listening skill. An independent sample t-test showed that the two groups were not statistically different from each other in the pre-test $(\mathrm{t}=-1.61, \mathrm{p} .=0.11>0.05)$, or in the post-test $(\mathrm{t}=-1.39, \mathrm{p} .=0.17>0.05)$. This suggests that both groups had similar L2 listening proficiency before and after CI training, in terms of the intensive listening ability. In combination with the paired-sample t-test, we might say that both groups have improved their intensive listening skill by the similar margin. Therefore, they did not exhibit statistical difference in either of the two tests. 
Based on the statistical analysis, it is safe to say that CI training is able to contribute to the improvement of trainees' intensive listening skill. The qualitative data collected in the questionnaires also attest to this finding. Amanda (all pseudonyms) from CG explained that "I strained myself to understand every word of the speech; otherwise, I cannot take any note, not to mention interpret it." Susie from EG also described how hard she tried to comprehend the speech in CI training: "it is different from multiple choice questions, where you just need to tick the right answer and move on. In interpreting, you actually have to hang on to every word."

Students' observations point to the importance of listening in the interpreting process, which concur with Gile's Effort Model (2009). For one thing, in the comprehension phase of CI, listening and analysis is the very first step, the insufficiency of which will lead to increased difficulty in the following steps. In order to guarantee that other steps such as note-taking and short-term memory operations as well as speech production can be successfully carried out, students especially beginners will try their utmost to cling to every single word and grasp even the smallest detail of the materials, just as what the students explained. The failure to catch any word would add to their psychological stress in the interpreting process. As a result, they pay close attention to every detail and attempt to digest it in the listening materials, hence the improvement of intensive listening skill. Secondly, in Gile's Effort Model, the three components occupy a varying portion of processing capacity, which means that they are competing for limited cognitive affordance (efforts, attention, etc.). Students are invariably forced to split their attention and properly allocate their effort to different components. In this way, they learn how to multitask in the interpreting process. By contrast, when they are taking a dictation test which is less challenging, more attention and processing effort could be saved for listening. Moreover, since "note-taking takes up a large proportion of processing effort in CI" (Gile, 2009), students might be able to concentrate more on listening once they just need to note down the original words directly instead of analyzing upcoming information and taking notes. This again justifies the improvement of intensive listening skill.

\subsection{Selective Listening Skill}

A paired-sample t-test showed that both groups scored significantly higher in the post-test than in the pre-test in summary writing (for $\mathrm{CG}, \mathrm{t}=3.56, \mathrm{p} .=0.002<0.01$; for $\mathrm{EG}, \mathrm{t}=10.45$, $\mathrm{p} .<0.001$ ). That means after 16 weeks of $\mathrm{CI}$ training, both of the groups improved their selective listening skill. An independent sample t-test showed that the two groups were not statistically different from each in the pre-test $(\mathrm{t}=-1.18, \mathrm{p} .=0.24>0.05)$; but significant difference was found in the post-test $(\mathrm{t}=-3.29, \mathrm{p} .=0.002<0.01)$. This suggests that in the pre-test $\mathrm{CG}$ and $\mathrm{EG}$ had the comparable proficiency level in terms of selective listening skill; but at the end of CI training, EG achieved much better improvement than CG.

We found this result a bit interesting and examined the qualitative data to uncover the reasons. As Jennifer from CG explained, "after this semester's CI training, I have formed the habit of applying the active listening skill to my interpreting exercises...I pay more attention to screening information and summarizing the main points." This comment is also collaborated by Jacky from EG, who wrote "now, whenever I listen to a speech, my primary attention is diverted to find out 'what's the point of this remark?"'. On the one hand, the fact that both groups made significant improvement in selective listening skill can be primarily attributed to the effect of active listening training. As is shown in Table 1., active listening training consists of six main aspects, namely identifying key words, chunking information, idea progression, casual relation, temporal and ordinal relation and visualizing structure. These aspects precisely correspond with the skills needed to perform a summary writing task, which requires the students to identify the key information and summarize the main points by grasping the logical clues and relation between sentences. Active listening training equips the students with selective listening skill to do well in this test question. On the other hand, the reason why EG significantly outperformed CG lies in the disparity of the two syllabi. In CG, training of the above six aspects is built in the interpreting skills training. In other words, interpreting skills training takes up the central position in classroom teaching whilst listening training acts as a supplementary exercise, accompanying interpreting skills training. Quite conversely, active listening training in EG is a stand-alone component and is thus given top priority and full dedication in the first six weeks. Students were especially trained to listen actively for each of the six key aspects in each lesson and were more concerned with mastering listening skills by this means. Undeniably, students in CG could also make progress in selective listening skill since they also received listening training in class. Yet after a careful comparison of the results and a thorough analysis of the gaps between the two groups, we can rationally reach the conclusion that the stand-alone training mode of active listening contributes more to enhancing students' selective listening skill.

\subsection{The Impact of CI Training on L2 Listening Competence}

Summarizing the findings discussed in the previous subsections, we believe that $\mathrm{CI}$ training does have a positive 
impact on the enhancement of L2 listening competence. However, a finer distinction needs to be made between different facets of listening abilities, when students are exposed to different interpreting training modes. Granted, in our study, students all improved their intensive and selective listening ability. However, the improvement margins achieved by the CG students were more noticeable in intensive listening skill than in selective listening skill. As regards EG students, they achieved very impressive L2 listening enhancement in terms of both intensive and selective listening ability. Based on the experiment results as well as reflections provided by the participants, we reveal that the biggest difference lies in the way active listening is trained in the syllabus. Students benefit more and achieve more obvious enhancement in selective listening ability when active listening is trained as a stand-alone component in the syllabus as opposed to trained as a built-in part of interpreting skills training.

\section{Implications}

\subsection{Implications for Interpreting Training}

The current study is especially insightful for interpreting training and education, as it helps to answer the question of which curriculum is more optimally designed. In this respect, both L2 proficiency and learning objectives of interpreting learners should be fully taken into account. If they have already demonstrated a relatively high level of language proficiency when admitted to interpreting training programs and aim to improve their interpreting skills to start or facilitate a professional career, both training modes are applicable. As a matter of fact, the built-in mode is adequate to satisfy their needs and more emphasis can be laid on career-oriented interpreting skills training, since improving language proficiency is not a top priority with them. Under such circumstance, the curriculum of MIIS (the language enhancement part could be excluded) and the two AIIC members can be maximally learnt from when an interpreting curriculum is to be designed.

However, despite the efforts made by major interpreting institutions in the West to distinguish interpreting training from language training, the situation in some parts of the world especially in China and Japan is quite different (Gile, 2009). As is mentioned earlier, studies from mainland China (Zhan, 2013), Hong Kong (Yan, Pan, \& Wang, 2010) and Korea (Sung, 2010) all suggest that interpreting learners (at undergraduate and postgraduate levels) take up interpreting training with the intention of improving their English proficiency to a varying degree. In fact, some researchers have reported that interpreting training at the undergraduate level focuses more on developing language skills than interpreting skills (Gonzalez, 2004) and undergraduates who take up interpreting training tend to be more interested in improving language proficiency than interpreting skills (Cho, 2007). This should be understood as a normal phenomenon given the fact that not everyone who receives interpreting training can become and work as a real interpreter after training. In this case, the stand-alone mode is evidently more applicable and effective than the built-in mode since it can improve learners' listening competence in a more comprehensive way (both listening for details and listening for gist). That is to say, active listening should be taught as an independent component in the curriculum intended for interpreting learners particularly undergraduates who hope to boost listening skills via interpreting training.

Thirdly, many interpreting student beginners cannot meet the language proficiency at the initial stage of training and L2 listening is apparently a stumbling block interfering with interpreting training (Zhong \& Wang, 2009). It is therefore more advisable to adopt the stand-alone mode to specially sharpen their active listening skills so as to guarantee the interpreting teaching quality. Although the built-in mode is also shown to have improved students' listening ability, the effect is less obvious in selective listening skill, which is more crucial in the listening and analysis process of CI. If interpreting trainers continue using the built-in mode to teach this group of learners, they would be likely to acquire certain interpreting skills and improve listening competence to some extent, but they may make less progress and achieve fewer results in interpreting performance than those trained in the stand-alone mode. This is because listening ability is the foundation of any interpreting training and can never be underestimated. At the end of interpreting training, many students fail the final professional exams because of "insufficient command of their working languages, not because of insufficient technical or cognitive skills" (Gile, 2009). In a word, the stand-alone mode is more conducive to enhancing listening competence, which is particularly essential for those who fall short of linguistic criteria from the very beginning.

The next question to solve is what practical suggestions can be offered to refine and improve the current CI curriculum in interpreting programs. As for those programs which do not set very strict requirements for learners' L2 proficiency such as MTI programs in China and some Translation and Interpretation (T\&I) programs in other parts of the world, the MIIS experience can be optimally drawn from. Electives for language enhancement can be provided in the first semester of postgraduate programs for students who might lack sufficient command of L2 proficiency and wish to lay a foundation for CI training. Such electives should offer a wide spectrum of contents related to language proficiency ranging from vocabulary, critical reading to 
summarizing and paraphrasing as well as text analysis. Moreover, they can also borrow the experience of $\mathrm{Lu}$ (2009), Xu (2010) or the syllabus of EG in this study to set up an interpreting listening course or at least make active listening training a stand-alone component before interpreting skills training is initiated. In the meantime, more exercises associated with L2 language training such as listening and speaking can be assigned to interpreting student beginners, which have been proven to be more beneficial for improving CI performance than other forms of exercises (Cai et al., 2015).

\subsection{Implications for L2 Listening Competence Enhancement}

This study also carries some positive implications for improving L2 listening pedagogy. As is previously mentioned, some students take up interpreting training because they hope and think that interpreting training can improve their L2 listening competence, but they are uncertain to what extent or in what ways it can do so. The current study is proof positive that interpreting training does improve learners' L2 listening competence, at least at the initial stage, and different training modes will generate different levels of improvement in different aspects of listening ability. Consequently, interpreting training lends itself to enhancing L2 listening competence. For instance, interpreting skills training such as shadowing, short-term memory training, note-taking as well as active listening training can be integrated into L2 listening classroom. These training methods are likely to supplement and diversify the existing strategies and methodology of L2 listening teaching proposed by the experts in this field (Vandergrift, 2004; Field, 2008).

In the first place, dictation and shadowing have much in common in that both tasks fit into the type of intensive listening, which targets at "phonology, syntax as well as lexis" and therefore involves accurate perception of specific details or a particular word (Rost, 2011). Intensive listening is one of the ways to promote language-focused learning, which serves to enhance listening proficiency (Rost, 2011). In view of this, dictation exercise can be coupled with shadowing exercise in L2 listening classroom to improve students' listening competence. In addition, shadowing exercise can be tentatively employed by teachers to elevate the accuracy of dictation when English majors are to cope with the dictation test question of TEM-4 in China. Furthermore, if teachers aim to help students enhance their ability of selective listening, then active listening training should be attached more value to. Students may benefit tremendously from being trained to listen for key information, identify temporal and ordinal relation, causal relation in active listening training, which is echoed by Morley's (1972) lesson content of selective listening instruction. Additionally, selective listening skill can also be sharpened via note-taking skill training. Note-taking skill is perceived as a critical "macro-skill in the lecture-listening comprehension process", sometimes interacting with writing, i.e. "the actual writing of the notes or subsequent writing based on the notes" (Rost, 2011, p. 188). Here, "subsequent writing based on the notes" is basically what summary writing after listening is. Thus, note-taking in interpreting training can also be adopted by teachers to improve students' L2 listening ability, especially selective listening skill.

\section{Conclusion}

Based on the quantitative and qualitative data of the current study, major findings in response to the research questions can be summarized as follows. Firstly, it can be concluded that CI training has a positive impact on the enhancement of interpreting student beginners' L2 listening competence. A careful comparison of the pre-test and the post-test results of the two groups of participants reveals that a 16-week CI training significantly improved students' listening ability, both intensive listening skill (listening for details) and selective listening skill (listening for gist). Additionally, different training modes exert different impact on the extent to which L2 listening ability is improved, depending on the way active listening is trained. When active listening was trained intensively as a stand-alone component for six weeks before other interpreting skills training started, students achieved more progress in selective listening skill development, as opposed to trained as a built-in part incorporated into interpreting skills training. Such findings serve to deepen our understanding of the impacts of CI training on L2 listening competence.

Despite its encouraging results, the present study is only the first step to revealing the impact of CI training on L2 listening competence enhancement. Future empirical studies need to be conducted on students with different L2 proficiency levels and diverse learning strategies, particularly examining whether CI training has the same magnitude of impact on L2 proficiency enhancement among different proficiency groups and how learners adopt different learning strategies in the built-in and stand-alone training modes.

\section{References}

Anderson, A., \& Lynch, T. (1988). Listening. Oxford, England: Oxford University Press.

Angelelli, C. (2006). Designing curriculum for healthcare interpreting education: A principles approach. In C. 
Roy (Ed.), New approaches to interpreter education (pp. 23-45). Washington, DC: Gallaudet University Press.

Angelelli, C. (2007). Assessing medical interpreters: The language and interpreting testing project. The Translator, 13(1), 63-82. http://dx.doi.org/10.1080/13556509.2007.10799229

Angelelli, C. (2008). Longitudinal studies and the development of assessment for advanced competencies. In L. Ortega, \& H. Byrnes (Eds.), The longitudinal study of L2 advanced capacities (pp. 264-278). New York, NY: Routledge.

Bowen, M. (1995). Interpreters and the making of history. In J. Delisle, \& J. Woodsworth (Eds.), Translators through history (pp. 245-277). Amsterdam and Philadelphia, The Netherlands: John Benjamins.

Cai, R. D., Dong, Y. P., Zhao, N., \& Lin, J. X. (2015). Factors contributing to individual differences in the development of consecutive interpreting competence for beginner student interpreters. The Interpreter and Translator Trainer, 9(1), 104-120. http://dx.doi.org/10.1080/1750399X.2015.1016279

Carroll, J. B. (1978). Linguistic abilities in translators and interpreters. In D. Gerver, \& H. W. Sinaiko (Eds), Language interpretation and communication. (pp. 119-129). New York, NY: Plenum Press.

Cho, S. E. (2007). Curriculum development in the undergraduate interpretation and translation program, The Journal of Translation Studies, 8(2), 163-191. http://dx.doi.org/10.15749/jts.2007.8.2.007

Field, J. (2008). Listening in the language classroom. Cambridge, England: Cambridge University Press.

Gile, D. (2009). Basic concepts and models for interpreter and translator training (Revised ed.). Amsterdam, The Netherlands: John Benjamins Publishing Company.

Gonzalez, D, M. (2004). Multiple voices in the translation classroom. Amsterdam, The Netherlands: John Benjamins Publishing Company.

Han, G. L., \& Chen, L. L. (2011). A Study on the interpreting teaching for Non-English majors. Foreign Language World, 1, $72-79$.

Hughes, A. (2003). Testing for language teachers (2nd ed.). Cambridge, England: Cambridge University Press.

Hunsaker, P. L., Alessandra, T., \& Alessandra A. J. (2008). The new art of managing people, updated and revised: Person-to-person skills, guidelines, and techniques every manager needs to guide, direct, and motivate the team. New York, NY: Simon and Schuster Inc.

Ilg, G., \& Lambert, S. (1996). Teaching consecutive interpreting. Interpreting, 1, 69-99. http://dx.doi.org/10.1075/intp.1.1.05ilg

Jesus, M., \& Mayor, B. (2015). L2 proficiency as predictor of aptitude for interpreting: An empirical study. Translation and Interpreting Studies, 10(1), 108-132. http://dx.doi.org/10.1075/ tis.10.1.06bla

Lu, X. C. (2009). Listening for English-Chinese interpreting: Cognitive-psychological model, skills and training

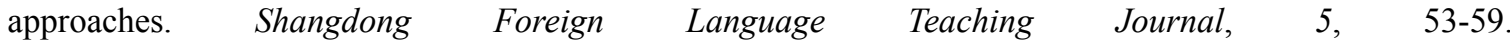
http://dx.doi.org/10.16482/j.sdwy37-1026.2009.05.016

Larsen-Freeman, D. (2006). The emergence of complexity, fluency, and accuracy in the oral and written production of five Chinese learners of English. Applied linguistics, 27(4), 590-619. https://doi.org/10.1093/applin/aml029

Morley, J. (1972). Improving aural comprehension. Ann Arbor, MI: University of Michigan Press.

Ping, H. (2011). A review of the annual conference on national master of translation and interpreting education in China. Chinese Translators Journal, 3, 31-33.

Rost, M. (2011). Teaching and researching listening (2nd ed.). Harlow, England: Pearson Education Limited.

Sawyer, D. (2004). Fundamental aspects of interpreter education: Curriculum and assessment. Amsterdam, The Netherlands: John Benjamins Publishing Company.

Sung, S. (2014). Using TED in the undergraduate interpreting classroom to enhance listening competence. STEM Journal, 15(1), 219-236.

Taylor, L., \& Geranpayeh, A. (2011). Assessing listening for academic purposes: Defining and operationalizing the test construct. Journal of English for Academic Purposes, 10, 89-101. http://dx.doi.org/10.1016/j.jeap.2011.03.002

Thelen, E., \& D. Corbetta. (2002). Microdevelopment and dynamic systems: Applications to infant motor 
development. In N. Granott, \& J. Parziale (Eds.), Microdevelopment: Transition processes in development and learning (pp. 59-79). Cambridge, England: Cambridge University Press.

Vandergrift, L. (2004). Listening to learn or learning to listen? Annual Review of Applied Linguistics, 24, 3-25. https://doi.org/10.1017/S0267190504000017

Wang, J. B. (2009). A needs survey of non-English major undergraduates in translation teaching: A case study of Shanghai Jiaotong University, Foreign Language World, 5, 72-96.

$\mathrm{Wu}, \mathrm{Z}$. (2016). An in-class peer-review model for interpreting courses. In J. Chen, \& L. Yang (Eds.), Interpreting studies: The way forward (pp. 83-91). Beijing: Foreign Language Teaching and Research Press.

Xu, R. (2010). Fostering “Attentive Listening Skills": Strategies for improving listening comprehension among undergraduate trainee interpreters. Chinese Translators Journal, 3, 43-47.

Yan, X., Pan, J., \& Wang, H. H. (2010). Learner factors, self-perceived language ability and interpreting learning: An investigation of Hong Kong tertiary interpreting classes. The Interpreter and Translator Trainer, 4(2), 173-196. http://dx.doi.org/10.1080/13556509.2010.10798803

Yang, M. Z. (2003). The effect of dictation practice on the language skills of Chinese EFL learners. Modern Foreign Languages, 26(3). 294-301.

Zhan, C. (2013). The study motives and experience of students in the Conference Interpreting Program in MTI-An empirical study on Guangdong University of Foreign Studies, Foreign Language World (5), 36-44.

Zhong, W. H., \& Wang, B. H. (2009). A foundation coursebook of interpreting. Beijing: Beijing Foreign Language Press.

\section{Web References}

Fu Jen Catholic University. (2016). Student admission brochure of postgraduate programs of Fu Jen Catholic University 2016. Retrieved from http://www.adm.fju.edu.tw/data/upload/Files/2016092914084.pdf

MIIS. (2016). How to Apply. Retrieved from http://www.miis.edu/admissions/apply

GDUFS. (2007). National Excellent Courses. Retrieved from http://www1.gdufs.edu.cn/jwc/bestcourse/kecheng/2/index.htm

Sichuan University. (2008). National Excellent Courses. Retrieved from http://cc.scu.edu.cn/G2S/Template/View.aspx?courseId=1307\&topMenuId=126070\&action=view\&type=1 \&name $=\&$ menuType $=1$ \& curfolid $=126192$

The University of Leeds. (2016). Program structure of Center for Translation Studies. Retrieved from https://www.leeds.ac.uk/site/custom_scripts/coursebrochure.php?file=http://www.leeds.ac.uk/download/212 /translation_studies_masters_academic_brochure

The University of Manchester. (2016). Masters Programs of School of Arts, Languages and Cultures 2016. Retrieved from http:/hummedia.manchester.ac.uk/schools/salc/brochures/2016/postgrad uate/PGT_Translation-2016.pdf

Translators Association of China. (2016). Name list of institutions newly-approved by Ministry of Education offering MTI program and bachelor degree programs of interpreting and translation. Retrieved from http://www.tac-online.org.cn/index/php?m=content\&c=index\&a=show\&catid=395\&id=2101

\section{Copyrights}

Copyright for this article is retained by the author(s), with first publication rights granted to the journal.

This is an open-access article distributed under the terms and conditions of the Creative Commons Attribution license (http://creativecommons.org/licenses/by/4.0/). 